\title{
The impact study of large sports events on mass sports consciousness training
}

\author{
LI Guang-xue \\ Department of Physical Education, China West Normal University \\ sunliang6@126.com
}

\begin{abstract}
In recent years, our country has hosted many large sports activities such as the Olympic Games in Beijing and Guangzhou national games. Large sports activities not only show sports technical level, but increase the enthusiasm of Chinese residents in participating in physical exercise. The larger number of our country's residents to participate in physical exercise, the more people who are concern about China's sports cause development. This study adopts tracking survey, questionnaire and mathematical statistics and other research methods, two sampling surveys are conducted in the next five years in Sichuan province on urban residents aged over 18, and multivariate linear regression model is applied to analyze the data collected. Research shows that the successful holding of sports events like The First Session of National Intelligence Games, the National Archery Championships, and Modern Pentathlon World Championships in Sichuan have a great influence on sports awareness and sports behavior of urban residents. Gender of residents has significant difference to the enthusiasm of physical exercise, but the participation of sports is more than those five years ago. Large sports events evidently affect the enthusiasm of residents' physical exercise. The more residents participate in sports activities, the more attention is paid to the development of sports undertakings in China. Most respondents have favorite sports, and their sports values are more scientific.
\end{abstract}

Keywords- Large sports activities; Sports consciousness; Sports behavior

\section{INTRODUCTION}

The result of National General Administration's Investigation Status of Chinese Mass Sports Present Situation in 1998 suggests that about seventy percent of residents have nothing to do with sports activities at that time and there's no enough attention and concern for social sports from all walks of life ${ }^{[1-3]}$. According to the results of Present Situation Investigation of Chinese Mass Sports in 2001, 65\% of people did not take part in any sports activities in 2000, and it found that the main factors influencing the residents participation in sports activities were lack of interest, insufficient understanding of sports activities importance and poor health. It is not hard to see from the survey results that residents' fitness consciousness is one of the important factors influencing sports participation.

Along with rapid development of social construction and economics in our country, our country pays more and more attention to sports cause development and the body qualities of Chinese residents ${ }^{[4-6]}$. In our country's 12 th fiveyear plan, it is explicitly pointed out that during the twelfth five-year is the key period to realize scientific and harmonious development, and is also an important stage to build sports power, promote sports course to realize a new development. The output value of our country's sports course from 2006 to 2011 is shown in Figure 1.

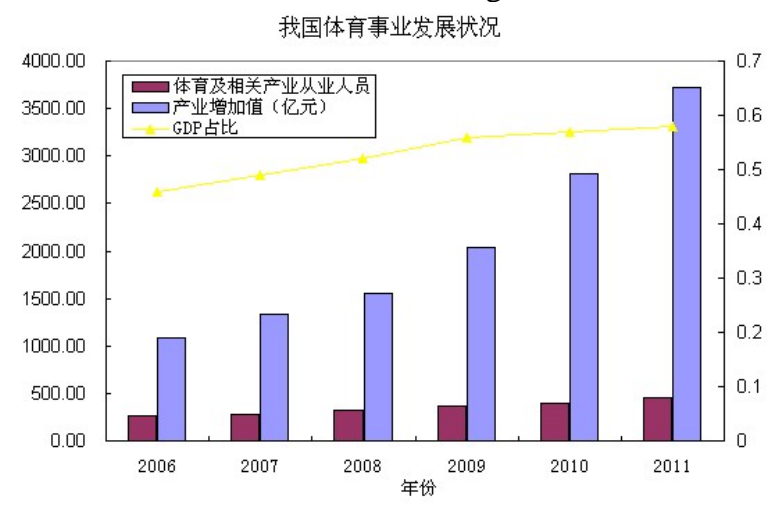

Figure 1 Development status of our country’s sports industry from 2006 to 2011

Under the background of current gradually rising of national fitness atmosphere, the positive role of social sports should be given full play to ${ }^{[7-9]}$. Promote mass sports consciousness cultivation by large sports events, and give full play to the media role of large sports event to attract more people to join in sports activities and to promote comprehensive improvement of residents' physical quality. Sichuan currently has many places to undertake various major sports events such as pentathlon, basketball, tennis, etc. so the research takes Sichuan province as a case to study the impact of large sports activities on the cultivation of mass sports awareness and sports activities ${ }^{[10-11]}$.

\section{RESEARCH OBJECT, DATA SOURCES AND RESEARCH METHODS}

\section{A. Research object and data sources}

This study selects urban and rural areas once held large sporting events in the past five years as the research area, such as five areas including Chengdu and Shuangliu county which held national championships or world championships. In selected research areas, urban and rural residents over 18 are the research object. Two surveys are done among respondents for sports participation and sports course awareness degree and so on.

The study distributed twice questionnaires in research area, altogether 5000 copies, of which 4122 questionnaires were collected, and the recovery degree was $82.44 \%$. Among them, 3978 are effective questionnaires, so the effective rate was $96.5 \%$. The descriptive statistics analysis results of the respondents are as shown in Table 3-1. 
Table 3-1 sample descriptive statistical analysis table

\begin{tabular}{|c|c|c|c|}
\hline $\begin{array}{l}\text { Statistical } \\
\text { variable }\end{array}$ & $\begin{array}{l}\text { classification } \\
\text { standards }\end{array}$ & $\begin{array}{l}\text { People } \\
\text { number }\end{array}$ & proportion \\
\hline \multirow{2}{*}{ Gender } & male & 2122 & $53.34 \%$ \\
\hline & female & 1856 & $46.66 \%$ \\
\hline \multirow{2}{*}{ Marital status } & married & 3011 & $75.69 \%$ \\
\hline & single & 967 & $24.31 \%$ \\
\hline \multirow{8}{*}{ Year of birth } & 1920-1929 & 21 & $0.53 \%$ \\
\hline & 1930-1939 & 327 & $8.22 \%$ \\
\hline & 1940-1949 & 671 & $16.87 \%$ \\
\hline & $1950-1959$ & 629 & $15.81 \%$ \\
\hline & 1960-1969 & 691 & $17.37 \%$ \\
\hline & 1970-1979 & 645 & $16.21 \%$ \\
\hline & 1980-1989 & 633 & $15.91 \%$ \\
\hline & 1990-1995 & 361 & $9.07 \%$ \\
\hline
\end{tabular}

\section{B. Research methods}

This research mainly adopts questionnaire investigation, comparative analysis and mathematical analysis and other research methods.

Collect and look up the literature related to mass sports consciousness and sports behavior collected from Chinese Academic Journal Full-text Database, CDDBFT, VIP and Chinese Sports Core Journals, sorting out the main factors influencing mass sports consciousness and formulate questionnaire as to provide theoretical basis for research and the original data questionnaire.

The study applies Eviews7.0 to respectively perform mathematical analysis of the raw data collected. By model test and reliability test, comparative analysis of the results got from two surveys are done to investigate the impact of large outdoor sports activities on local mass sports consciousness training.

\section{RESEARCH VARIABLES AND RESEARCH MODEL}

\section{A. Research variables}

This study selected the sports consciousness of the research object in research area as dependent variable $y$, respondents' exercise frequency per week $\mathrm{x} 1$, annual participation in major sports events $\mathrm{x} 2$, the awareness of sports x3, weekly hours to watch sports program x4, concern about the construction of community sports $\mathrm{x} 5$ as a return item to study the impact of large outdoor sports activity on residents' sports consciousness and sports activities.

\section{B. research model}

This study uses multiple linear regression models to analyze the impact of large outdoor sports activity on residents' sports consciousness and sports activities, and the specific formula of the model is as follows: $y_{i}=\beta+\alpha_{i} x_{i}$

In Formula (3.1), the dependent variable $\mathrm{y}$ is $\mathrm{N} \times 1$ dimensional column vector, return item xi is the $\mathrm{N} \times 5 \mathrm{~d}$ matrix, $\alpha_{i}$ is regression coefficient, and $\beta$ is a random disturbance column vector. In order to investigate the suitability of the model, the gap between the estimated value and actual value is denoted by residual error, and the specific calculation formula is as follows:

$$
\mu_{\mathrm{i}}=\hat{y}_{i}-y_{i}=\hat{y}_{i}-\beta-\alpha_{i} x_{i}
$$

The calculation formula of model regression coefficient based on residual error estimation is as follows:

$$
R S S=\sum_{i=1}^{N} u_{i}^{2}=\sum_{i=1}^{N}\left(\hat{\mathrm{y}}_{i}-\beta-\alpha_{i} x_{i}\right)^{2}
$$

The variance calculation formula of the random disturbance item is as follows:

$$
\sigma^{2}=\frac{\sum \mu_{i}^{2}}{N-k-1}
$$

\section{Model test and reliability test}

This research tests the significance by applying $\mathrm{F}$ statistic method, and the specific calculation formula is as follows:

$F=\frac{\sum_{i=1}^{N}\left(y_{i}-\bar{y}_{i}\right)^{2} / k}{\sum_{i=1}^{N}\left(\hat{y}_{i}-\bar{y}_{i}\right)^{2} /(N-K-1)}$

The significance indicators of regression item are calculated based on $\mathrm{F}$ statistics method in order to confirm the credibility of the regression results.

\section{EMPIRICAL RESEARCH RESULTS}

By comparing and analysis of the mass sports awareness evaluation score before and after five years in study area, this study, analyze the influence degree of large sports events on mass sports awareness and sports activities, study the multiple regression analysis of the two set of sample data respectively, and compare the dependent variable estimates.

\section{A. Descriptive analysis}

Model test and reliability test are carried out respectively on two groups of sample data. The descriptive results obtained are as shown in Table 4-1. 
Table 4-1 Descriptive results

\begin{tabular}{lll}
\hline Dependent Variable: $\mathrm{Y}$ & & \\
\hline Included observations & $\mathrm{N} 1=1989$ & $\mathrm{~N} 2=1989$ \\
R-squared & 0.7231 & 0.7726 \\
Mean dependent var & 3.4107 & 3.8173 \\
Adjusted R-squared & 73.1435 & 73.5711 \\
S.D. dependent var & 3.4114 & 3.7814 \\
S.E. of regression & 3.71 .39 & 4.1527 \\
Sum squared resid & 65.1442 & 61.7117 \\
Akaike info criterion & 3.1071 & 3.0611 \\
Schwarz criterion & 4.1686 & 4.2398 \\
F-statistic & 1.5469 & 1.5579 \\
Prob(F-statistic) & 0.0223 & 0.0312 \\
Durbin-Watson stat & 0.7934 & 0.8017 \\
\hline
\end{tabular}

From Table 4-1, it can be seen that model R2 values are respectively 0.7231 and 0.7726 , which shows that during two regression analysis processes, what can be explained for the dependent variable by the return item are $72.31 \%$ and $77.26 \%$, respectively, which can explain high part proportion. That means the selection of independent variables is appropriate, and the regression results of the research have a certain reference value. By the combination of the model's AIC and SC test values, it can be seen that the models this study applied have passed the inspection of effectiveness of Akaike information criterion and Schwarz information criterion, so the model structure is suitable for the sample data analyzed. Dependent variable y's P value are 0.0223 and 0.0223 , which shows that it is reliable if the two estimates of dependent variable in two regression analysis are under the significance level of 5\%, namely if the dependent variable of the model in the study is very close to the actual value, the research results are reliable.

\section{B. Empirical result analysis}

Table 4-2 Empirical research results

\begin{tabular}{lll}
\hline Y & N1 & N2 \\
\hline Variable & Coefficient & Coefficient \\
C & -72.3219 & -77.7032 \\
x1 & $15.7189^{* *}$ & 18.5753 \\
x2 & $11.2023^{* *}$ & $13.0676^{* * *}$ \\
X3 & 9.9973 & $12.0676^{* *}$ \\
x4 & $0.5753^{* *}$ & $0.7512^{* *}$ \\
x5 & 0.5475 & 0.8747 \\
\hline
\end{tabular}

As can be seen from Table 4-2, in the first time regression analysis results, it is reliable if the variables $\mathrm{x} 1, \mathrm{x} 2$, and $\mathrm{x} 4$ are under $5 \%$ significance level. In the second regression analysis results, it is reliable if the variables $\mathrm{x} 2, \mathrm{x} 3$ and $\mathrm{x} 4$ are under $5 \%$ significance level, which means that the two regression analysis results are of higher reliability, and can carry out comparative analysis. The greater is the regression coefficient, the greater is the impact of dependent variable on regression variables, so it can be seen that the change is evident before and after the five years in respondents exercise frequency every week, average participation in large sports events and sports events per year and consciousness of sports events. It means that before and after large outdoor sports activities, the local mass's enthusiasm to take exercise, participate in sports activities, and the attention of it are promoted. In other words, the hosting of large sports events significantly improved the local people's consciousness of sports, and improved the enthusiasm of the mass's participation in sports activities. But in two regression analysis results, the coefficients of variables $\mathrm{x} 4$ and $\mathrm{x} 5$ are relatively small, which shows that the influence of large sports events on mass's fond degree is not obvious, and people's focus on the construction of community sports is still insufficient.

\section{Comparative analysis}

According to the results of two regression analysis, the results of sports consciousness score comparison of the mass of different age are shown in Figure 2

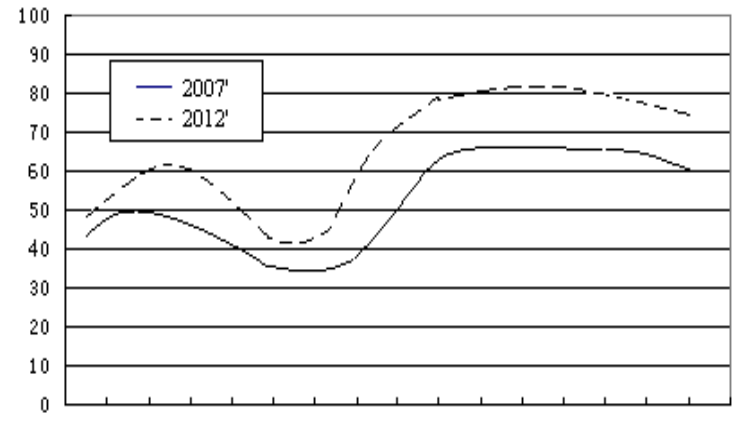

$\begin{array}{llllllllllllllll}15 & 20 & 25 & 30 & 35 & 40 & 45 & 50 & 55 & 60 & 65 & 70 & 75 & 80 & 85 & 90\end{array}$

Figure 2 Comparative analysis results

It can be seen from Figure 2, there is evident difference between mass sports awareness survey results in 2007 and 2012 in the study area. The sports consciousness of all ages of people in 2012 are higher than that in 2007, which suggests that the host of large outdoor sports activities has comparatively obvious effect on the local people's consciousness of sports training. At the same time, it can be seen from the comparison results that people's sports consciousness around the age of 40 to 50 is the weakest. The number of participating in sports activities and physical exercises also is less. The elderly population is the highest sports consciousness population. However the middle-aged and young have relatively weak sports consciousness. Through the interview, it can be found that although young people love sports, but with aging, the gradually increasing pressure of family and work lead to the fact that the middleaged in career gold period invest the least time and energy in sports activities and physical exercise. The vigorous development of sports undertakings in China requires full attention, therefore our country should widely encourage the masses to participate in active sports, and at the same time, 
focus on the sports activities of middle-aged people to avoid the problem of becoming unhealthy in young age largely appear in middle-aged people.

\section{CONCLUSION}

In order to entirely fulfill the scientific development outlook, give full play to sports undertakings' important role in improving people's livelihood and promoting social progress. Our country should actively promote comprehensive, balanced and sustainable development of sports industry; strengthen large sports events' cultivating function of the sports consciousness in all people in order to achieve the goal of construction of sports power.

\section{REFERENCES}

[1] G. Eason, B. Noble, and I. N. Sneddon, "On certain integrals of Lipschitz-Hankel type involving products of Bessel functions," Phil. Trans. Roy. Soc. London, vol. A247, pp. 529-551, April 1955. (references)

[2] J. Clerk Maxwell, A Treatise on Electricity and Magnetism, 3rd ed., vol. 2. Oxford: Clarendon, 1892, pp.68-73.
[3] I. S. Jacobs and C. P. Bean, "Fine particles, thin films and exchange anisotropy,” in Magnetism, vol. III, G. T. Rado and H. Suhl, Eds. New York: Academic, 1963, pp. 271-350.

[4] K. Elissa, “Title of paper if known,” unpublished.

[5] minutes

[6] R. Nicole, “Title of paper with only first word capitalized," J. Name Stand. Abbrev., in press.

[7] Y. Yorozu, M. Hirano, K. Oka, and Y. Tagawa, "Electron spectroscopy studies on magneto-optical media and plastic substrate interface,” ASME Transl. J. Magn. Japan, vol. 2, pp. 740-741, August 1987 [Digests 9th Annual Conf. Magnetics Japan, p. 301, 1982].

[8] M. Young, The Technical Writer's Handbook. Mill Valley, CA: University Science, 1989.

[9] Electronic Publication: Digital Object Identifiers (DOIs):

Article in a journal:

[10] D. Kornack and P. Rakic, "Cell Proliferation without Neurogenesis in Adult Primate Neocortex,” Science, vol. 294, Dec. 2001, pp. 2127 2130, doi:10.1126/science.1065467.

Article in a conference proceedings:

[11] H. Goto, Y. Hasegawa, and M. Tanaka, "Efficient Scheduling Focusing on the Duality of MPL Representatives," Proc. ASME Symp. Computational Intelligence in Scheduling (SCIS 07), ASME Press, Dec. 2007, pp. 57-64, doi:10.1109/SCIS.2007.357670. 